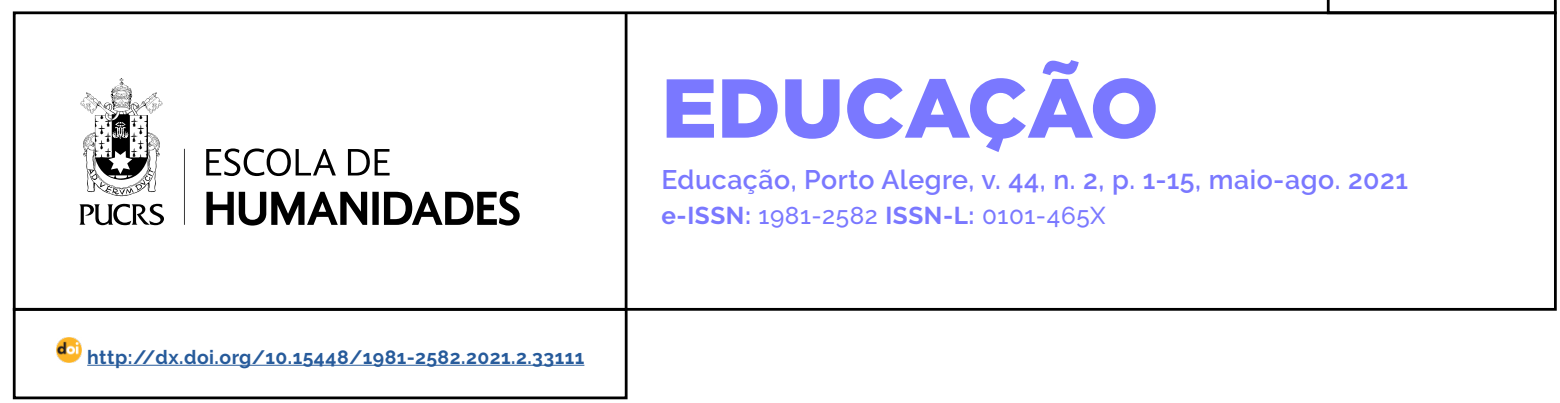

SEÇÃO: OUTROS TEMAS

\title{
O legado da Educação Popular na formação da individualidade para si nas classes da Educação de Jovens e Adultos
}

\author{
The legacy of popular education in the formation of individuality for it in the classes of the \\ Youth and Adult Education \\ El legado de la educación popular en la formación de la individualidad para si en las \\ clases de la Educación de Jóvenes y Adultos
}

\author{
Maria Luiza Luiza \\ Ferreira Duques ${ }^{1}$ \\ orcid.org/0000-0002-9949-5183 \\ luizaduques@hotmail.com
}

\section{Cláudio Eduardo Félix \\ dos Santos ${ }^{1}$}

orcid.org/0000-0003-0545-1102

cefelix@gmail.com

Recebido em: 28 dez. 2018. Aprovado em: 22 abr. 2021. Publicado em: 16 set. 2021.
Resumo: Este artigo delineia uma discussão teórica sobre a formação da individualidade para si na Educação de Jovens e Adultos, por meio de contribuições emanadas da Educação Popular. Entendendo a individualidade em si como a sintese espontânea das relações sociais e a individualidade para si como a síntese consciente de tais relações, apresentamos a individualidade para si como relevante possibilidade da formação do indivíduo da Educação de Jovens e Adultos, a partir da apropriação das produções humanas. Para tanto, lança-se mão de um retrospecto histórico, no sentido de melhor compreender os sentidos das iniciativas de Educação Popular e suas contribuições para a formação da individualidade para si nos educandos da Educação de Jovens e Adultos. Espera-se, com base nas construções deste texto, que os percursos já percorridos pela Educação de Jovens e Adultos, desde as iniciativas de Educação Popular até o momento atual de institucionalização da modalidade, contribuam com a promoção de uma Educação de Jovens e Adultos que possibilite, aos sujeitos sociais, o desenvolvimento de uma relação educativa consciente e não alienada consigo mesmos e com o mundo circundante, o que enseja a transição da individualidade em si para a individualidade para si.

Palavras-Chave: Educação Popular, individualidade para si, Educação de Jovens e Adultos

Abstract: This article outlines a theoretical discussion on the formation of individuality for oneself in Youth and Adult Education from contributions emanating from Popular Education. Understanding individuality itself as the spontaneous synthesis of social relationships and individuality for itself as the conscious synthesis of such relationships, we present individuality for itself as a relevant possibility for the formation of the individual in Youth and Adult Education, based on the appropriation of human productions. Therefore, a historical review is used, in order to better understand the meanings of popular education initiatives and their contributions to the formation of individuality for themselves in Youth and Adult Education students. Based on the constructions of this text, it is expected that the paths already taken by Youth and Adult Education, from Popular Education initiatives to the current moment of institutionalization of the modality, contribute to the promotion of an Youth and Adult Education that enables social subjects to develop a conscious and non-alienated educational relationship with themselves and with the surrounding world, which gives rise to the transition from individuality in itself to individuality in itself.

Keywords: Popular Education, individuality for you, Youth and Adult Education. 
Resumen: Este artículo esboza una discusión teórica sobre la formación de la individualidad de uno mismo en la Educación de Jóvenes y Adultos a partir de aportes que emanan de la Educación Popular. Entendiendo la individualidad en si misma como la síntesis espontánea de las relaciones sociales y la individualidad en sí misma como la sintesis consciente de tales relaciones, presentamos la individualidad en si misma como una posibilidad relevante para la formación del individuo en Educación de Jóvenes y Adultos, a partir de la apropiación de las producciones humanas. Por lo tanto, se utiliza una revisión histórica, con el fin de comprender mejor los significados de las iniciativas de educación popular y sus aportes a la formación de la individualidad de si mismos en los estudiantes de Educación de Jóvenes y Adultos. A partir de las construcciones de este texto, se espera que los caminos ya recorridos por Educación de Jóvenes y Adultos, desde las iniciativas de Educación Popular hasta el momento actual de institucionalización de la modalidad, contribuyan a la promoción de una Educación de Jóvenes y Adultos que permita a los sujetos sociales desarrollar una conciencia y no -relación educativa alienada consigo mismos y con el mundo circundante, que da lugar a la transición de la individualidad en si a la individualidad en sí. Palabras clave: Educación Popular, jndividualidad para ti, Educación de Jóvenes y Adultos.

\section{Introdução}

A Educação Popular pode ser tomada como uma corrente de pensamento e de resistência cultural que eclodiu na América Latina, gestada na emergência de diversas formas de organização e lutas populares, e alcançou diversos paises, como é o caso do Brasil. Desde suas origens, essa proposta de educação se coloca como mecanismo de luta contra a hegemonia do capitalismo e de critica ao colonialismo cultural e educacional, buscando novos padrões de relação com o saber em educação. É nesse sentido que, no Brasil, a Educação Popular nasceu e se desenvolveu em um contexto de efervescência dos movimentos populares, fundamentados na cultura popular e nos saberes da experiência do povo.

As propostas de Educação Popular, imbuidas dos sentidos da Pedagogia Libertadora freireana, consistiram em importantes suportes teóricos para as práticas realizadas por parte dos movimentos sociais no Brasil, sobretudo nas décadas de 1950 e 1960, em que as formulações freireanas contribuiram de modo decisivo para a consolidação da Educação Popular como referência de educação. As referências do pensamento freireano nas propostas de Educação Popular abarcaram diversas iniciativas, que valorizavam os alijados dos processos sociais e os impedidos de interpretar o mundo por diversas limitações, entre as quais a de ler e escrever. Nessa perspectiva, o trabalho do educador Paulo Freire (1921-1997) propôs uma educação de adultos que levasse em consideração as caracteristicas socioculturais das classes populares. Daí a necessária e legítima articulação entre Educação Popular e Educação de Jovens e Adultos (EJA).

Eis que essas percepções de uma relação identitária da Educação Popular com a EJA, atreladas à condição de emancipação atribuída aos processos educativos, remetem à modalidade de EJA, voltada, eminentemente, para o conjunto de individuos excluidos de muitos direitos sociais, dentre os quais o direito a educação. Partindo dessa compreensão, este estudo tem como escopo discutir a formação da individualidade para si na EJA, por meio de contribuições emanadas da Educação Popular. Para isso, é preciso incidir um olhar específico sobre os educandos da modalidade, reconhecendo-os essencialmente em sua condição de classe trabalhadora e oprimida e que necessita, pois, dos processos de escolarização para efetivarem as apropriações da humanidade.

Os estudos aqui desenvolvidos sobre a individualidade para si, que carecem de uma menção, ainda que breve, sobre a individualidade em si tomam como referências mais substanciosas as produções de Duarte (1999, p. 2013). A adoção, neste texto, da individualidade para si como categoria para o processo de formação dos indivíduos jovens e adultos, parte do entendimento de que a individualidade para si "expressa no âmbito da formação do indivíduo um processo de desenvolvimento que se inicia pela sintese espontânea das relações sociais (a individualidade em si), rumo a uma sintese consciente das relações sociais (a individualidade para si)" (Duarte, 2013, p. 09). A formação do individuo para si e, nesse caso, dos educandos jovens e adultos que pretendemos explorar é na esteira de Duarte (2013), a formação de pessoas capazes de desenvolver uma relação consciente com o gênero humano. 
Para uma maior possibilidade de compreensão acerca da individualidade em si e para si, pensemos em algumas situações: mediante as objetivações genéricas em si, os homens e mulheres produziram novos meios de se colocar na natureza, de modo que essas produções, cada vez mais complexas, não visassem a satisfação de necessidades imediatas. A essas produções, que demandam um considerável nivel de complexidade psíquica para serem apropriadas, chamamos de objetivações genéricas para si, dentre as quais Duarte (2013) cita a ciência, a arte e a filosofia. Se é verdade que a apropriação das objetivações do gênero humano demanda um longo tempo, não sendo, portanto, imediatas, também é certo que todo individuo forma sua individualidade em si, mediante à apropriação, desde as fases mais pueris da vida, das objetivações genéricas em si. A individualidade para si se forma devido à apropriação das objetivações genéricas para si, logo, do mesmo modo que o gênero humano elevou-se de sua genericidade em si até sua genericidade para si, o individuo também deve se elevar de sua individualidade em si para sua individualidade para si.

Segundo Duarte (2013), para que seja produzida a individualidade, é necessário o desenvolvimento de um processo dialético entre apropriação e objetivação da realidade. Destarte, a produção dos mecanismos promotores da satisfação das necessidades humanas constituem as determinações que produzem a individualidade. Então, a relação entre apropriação e objetivação, uma vez resultante da prática social historicamente acumulada, se configura como elemento cultural, mediado pela atividade dos sujeitos e pela relação com a cultura. Depreende-se disso a compreensão de que a apropriação das objetivações empreendidas pelo homem depende cada vez mais da qualidade das mediações, necessárias a sua formação enquanto um ser social (Duarte, 2013). Nesse ponto, se evidencia a função da escola como instituição responsável pela formação necessária às apropriações e objetivações humanas.

A educação escolar e, no caso específico deste estudo, a EJA, por aquilo que deve ensinar aos jovens e adultos, desempenha um papel de suma relevância na mediação entre individuo e apropriação das objetivações do gênero humano. Por meio da educação escolar os individuos acessam a produção da humanidade, motivo que induz a relação da função histórica da escola na formação de uma individualidade para si.

Por esse viés, a centralidade das discussões aqui estabelecidas está nas reflexões sobre o legado da Educação Popular na formação da individualidade para si nas classes da EJA.

\section{Interfaces da Educação Popular com}

a Educação de Jovens e Adultos: princípios para a formação da individualidade para si

Pensar na Educação Popular em interfaces com as especificidades da EJA, no que concerne a seleção de conteúdos, bem como as práticas de libertação, é pensar, também, nas possibilidades que esses processos educativos podem alcançar na elevação dos educandos. Tendo por referência as "formas superiores de recepção e reprodução da realidade" (Lukács, 1966, p. 11), a educação escolar se ocupa das objetivações do gênero humano, que, no caso da EJA, uma vez articuladas ao objetivo de libertação proposto pelos movimentos de Educação Popular, possui potencial para promover a apropriação para si das formas superiores de recepção e reprodução da realidade. Ao problematizar, na instituição de EJA, as ambivalências e as perspectivas da produção de conhecimentos em diálogo com o legado da Educação Popular, abre-se espaço para o reconhecimento do lugar de classe social do educando da EJA, de que modo que a escolha dos conteúdos converse com esse lugar, como tenciona a perspectiva político pedagógica da Educação Popular e de seu legado.

Considerando a formação de educandos jovens e adultos trabalhadores, os pressupostos da Educação Popular, uma vez apropriados pela modalidade de EJA, possuem potencial de ser instrumentos capazes de desencadear a relação consciente dos indivíduos com o gênero humano, o que, consequentemente, levará tais 
indivíduos à formação da individualidade para si. A questão que colocamos, quando propomos uma discussão focalizada na EJA em articulação com a Educação Popular, é no sentido de pensar a transmissão dos conhecimentos de forma não alienada e de modo a combater o caráter burguês da escola. No nosso entendimento, ao se apropriar de pressupostos da Educação Popular, a EJA, enquanto modalidade da educação escolar, pode agregar elementos de uma educação crítica, que, não negando aos educandos os conhecimentos clássicos necessários ao desenvolvimento humano, se coloque a favor da transformação desses individuos. Lançando mão das formulações de Duarte (2012, p. 200), reforçamos a afirmação da necessidade de pedagogias que "superem a educação escolar em suas formas burguesas sem negar a importância da transmissão, pela escola, dos conhecimentos mais desenvolvidos que já tenham sido produzidos pela humanidade".

Para melhor compreendermos essa discussão, tentaremos discutir as especificidades das objetivações genéricas em si e para si. Como já dito, as objetivações genéricas em si abarcam os traços mais gerais da sociabilidade humana, que servem aos homens como "[...] seu sistema de referência primário" (Heller, 1998, p. 229). As objetivações genéricas em si condizem, pois, com o ingresso dos indivíduos ao mundo socializado.

Dito de outro modo, as objetivações genéricas em si constituem a base da apropriação do gênero humano e sem elas os indivíduos não existem em sua humanidade, ao passo que as objetivações genéricas para si "são ontologicamente secundárias, as sociedades não as possuem necessariamente" (Heller, 1998, p. 232), o que significa que é possível que vivam em sociedade sem necessariamente se apropriarem dessas objetivações. Essa é uma questão presente na sociedade capitalista. Basta pensarmos que apenas uma pequena parcela da população mundial possui condições objetivas de se apropriar das objetivações genéricas para si, enquanto que a maioria dos indivíduos vive em condições precárias de existência, limitando-se a sua individualidade em si. Imersos nessa imensa maioria, que vive em situações precárias, estão diversos educandos jovens e adultos, que, se não pela inserção nos processos de escolarização, dificilmente teriam meios de extrapolar o âmbito da individualidade em si.

Obviamente, não estamos concebendo a individualidade em si como um empecilho à formação da individualidade para si, posto que, como já exposto em outros momentos neste texto e como afirmado por Duarte (1999, p. 179), "o indivíduo para si não elimina de sua vida o âmbito da individualidade em si, que é preponderantemente cotidiana". A grande questão está no fato de que, no sistema capitalista, a individualidade em si constitui-se no elemento central da vida dos indivíduos. Daí a necessidade de uma educação crítica capaz de romper com os processos de alienação e avançar na direção de uma contra hegemonia. É nesse sentido que buscamos apresentar as interfaces entre a Educação Popular e a EJA na promoção da formação da individualidade para si dos educandos jovens e adultos.

Desenvolver estudos com o intuito de afirmar a importância e a atualidade da Educação Popular na formação da individualidade para si nas classes da EJA nos coloca diante da imperiosa necessidade de revisitar a história das lutas sociais e populares, que implicaram, e ainda implicam, nos processos educativos desenvolvidos com a população de jovens e adultos.

Concebida como um extenso e profundo processo direcionado a grandes contingentes populacionais, que ao passo que impulsionava as pessoas a acreditarem na possibilidade de mudança e melhoria de vida, alimentava o desejo de lerem o mundo e, ao lê-lo, transformá-lo (Freire, 1977), a Educação Popular se traduz em um importante espaço de enfrentamento e luta por transformação.

O compromisso com as classes populares desencadeou, essencialmente a partir da década de 1950, vários movimentos da Educação Popular, nos quais a alfabetização no bojo da proposta do método de Freire tornou-se o fio condutor da emancipação dos setores desfavorecidos. Desse modo, por um lado, as práticas de alfabetização realizadas na perspectiva freireana denunciavam o caráter reprodutivista e classista da ideologia 
dominante; por outro lado, e na maioria das vezes, conjuntamente, foi por meio da Educação Popular que se mostrava vivo o compromisso de tornar as condições de vida dos setores populares instrumentos ilustrativos das situações de aprendizagem, presentes nos conteúdos dos materiais pedagógicos e nas análises conjunturais e estruturais que se faziam a época.

Com isso, as ações de Educação Popular deram corpo, junto aos variados setores populares, aos processos de discussão e reflexão da conjuntura política, econômica, social e educacional, tencionando, pois, a conscientização e participação popular. Assim, as ações da Educação Popular, aliadas ao EJA, nessa concepção histórico-critica-social, desencadearam o surgimento de novos métodos e teorias, de inspiração e historicidade nacionais, substituindo os modelos, até então, importados e conferindo significados concretos às ações nos diversos campos e, entre eles, no campo da educação.

Nesse contexto, os niveis de contribuição e incorporação do legado da Educação Popular às práticas docentes da EJA, num processo de sistematização de escolarização, é plenamente problematizável, essencialmente se for levado em conta as possibilidades de conexão dos conhecimentos científicos formais, necessários à formação da individualidade para si (Duarte, 2013), com os saberes e fazeres da experiência. No âmbito das contribuições que o campo da Educação Popular possa prestar à EJA, Arroyo (2001) menciona a necessidade de um olhar específico sobre os educandos dessa modalidade e, essencialmente, o reconhecimento de sua condição como classe trabalhadora e oprimida para a manutenção desse legado. O campo da EJA, de acordo esse mesmo autor, seja em termos legais ou em termos conceituais, foi capaz de imprimir e incorporar a herança da Educação Popular em sua concepção pedagógica e jurídica atual, contudo, a possibilidade de perda desses referenciais nos programas e projetos oficiais de escolarização aplicados nas redes de ensino não pode ser desconsiderada.

Com a reafirmação do legado da Educação Popular, procura-se reconhecer a EJA como uma etapa dotada de especificidades, assegurando, em sua normatização legal, pedagógica e política, o entendimento dos educandos trabalhadores como sujeitos que trazem, em suas existências, uma bagagem social e cultural que merece ser considerada na EJA.

Nesse sentido, discutir sobre a Educação Popular ao lado da EJA significa pensar na relevante presença da dimensão popular no cenário brasileiro. As conexões possiveis de serem estabelecidas no âmbito da experiência e da Educação Popular, em direção a uma modalidade educativa que considere o ideário de libertação e politização de educadores e educandos, abrem precedentes para se pensar na contribuição dos conhecimentos populares de outrora, para o desenvolvimento de ações educativas no momento atual. Nessa perspectiva, Arroyo (2001) reforça a importância de práticas de Educação Popular nas propostas de EJA, ao afirmar que a herança legada pelas experiências de EJA, inspiradas no movimento de Educação Popular, não é apenas digna de ser lembrada, rememorada e incorporada, quando pensamos em políticas e projetos de EJA, mas continua tão atual quanto nas origens de sua história, nas décadas de 1950 e 1960, pois a condição social e humana dos jovens e adultos, que inspiraram essas experiências e concepções, também continua atual. Tão atuais que não perderam sua radicalidade, haja vista que a realidade vivida pelos jovens e adultos populares continua radicalmente excludente.

Os jovens e adultos da EJA são, em sua maioria, trabalhadores, que desde muito cedo trabalham para sobreviver. São sujeitos de direitos que gozam de poucos direitos, que vêm de classes populares, de origem humilde e de familias geralmente numerosas. Esses jovens e adultos, em quase toda totalidade, apresentam uma trajetória muito especifica, uma história de exclusão, opressão e marginalização. Buscam, na escolarização, perspectivas de liberdade e emancipação no trabalho e na educação. É essa especificidade da situação social, étnica, racial, cultural e econômica que precisa ser referência para a construção da EJA, e são nessas bases que as propostas de Educação Popular floresceram. 
Desse modo, conceber a EJA em interface com a Educação Popular significa ancorar-se numa concepção de educação fundamentada na transformação histórica e cultural, e nisso reside a sua dimensão política. Mediante esse aspecto, é importante pensar a EJA no seu sentido de atuação partindo da realidade dos oprimidos, do universo das significações populares, para, então, conceber a modalidade em sua articulação, com os referenciais teóricos construídos pela cultura científica. Nesse ponto reside a importância de se pensar no desenvolvimento da individualidade para si dos educandos como condição da elevação de seus patamares de existência.

A educação escolar, aqui representada pela modalidade de EJA, por meio do ensino dos conteúdos do saber sistematizado, apresenta-se como uma possibilidade de contribuição para transformação das relações sociais, já que, a partir do momento em que os educandos apropriam-se dos conhecimentos produzidos pela humanidade, passam a ter condições de mudar a prática social.

Estando a Educação Popular centrada na ação prática, é possivel que seus desdobramentos e sua fundamentação epistemológica e pedagógica possam atingir a EJA, de forma a acoplar o praticismo, necessário às lutas sociais, a um corpus teórico que considere o conhecimento científico, necessário às objetivações e apropriações genéricas da humanidade. Como postulado por Saviani e Duarte (2012, p. 4), deve, a escola, transmitir o acúmulo social de experiências e todo o patrimônio cultural da humanidade, para que, assim, o processo revolucionário possa ser fundamentado como "[...] uma das mais expressivas formas de criatividade humana", devendo ser amparado por ações transformadoras da realidade.

As raizes da Educação Popular e a importância que ela possui junto a processos de libertação e emancipação são elementos suficientes para entender essa proposta de educação como detentora de um importante legado para iniciativas que se baseiam na formação e empoderamento de grupos historicamente excluidos, como é o caso dos educandos da EJA.

Para melhor compreender os desdobramentos da Educação Popular por meio das campanhas e programas educacionais, germinados a partir dos ideais populares e das implicações das políticas públicas para a educação, é importante delinear uma breve trajetória da EJA apontando avanços e refletindo sobre os possiveis retrocessos que permearam as campanhas educativas para a EJA, considerando, para efeito deste estudo, o enfoque temporal, que contempla desde as primeiras iniciativas de educação de adultos até os movimentos de educação e cultura popular, ocorridos entre as décadas de 1950 e 1960, por serem as décadas que assinalam, de modo mais proficuo, o encontro da EJA com a Educação Popular.

\section{Trajetória histórica da Educação de Jovens e Adultos (das primeiras iniciativas aos movimentos de educação da década de 1960): encontros com a Educação Popular}

A EJA se gesta por meio de uma história muito tensa, carregada por interesses bastante diversificados e, em boa parte das vezes, não consensuais

As origens da educação de adultos estão no Brasil-Colônia², representadas pela figura dos jesuitas que "instruiam" os jovens e adultos por meio da transferência, aos nativos, das normas de comportamento em sociedade e técnicas de trabalho para atender às necessidades da colônia. Esse processo educacional cristão funcionava como uma prática educativa universalizadora e configurou-se como o primeiro sistema educacional da, então, América Portuguesa. Essa escolarização religiosa, contudo, buscava moldar uma nova sociedade, com vistas ao atendimento dos anseios da economia da época.

No âmbito dos direitos legais, a Constituição Brasileira de 1824 firmou a garantia da instrução

2 É importante esclarecer que as ações de transferência e adaptação dos conhecimentos religiosos aos habitantes originais da América, ocupada pelos portugueses e espanhóis, tinham as crianças como público alvo, mas, no caso da América Portuguesa, os religiosos também exerciam sua ação educativa missionária junto aos adultos. 
primária e gratuita a todos os cidadãos, entendendo-se que, para aquele contexto, cidadania restringia-se aos homens livres e libertos. Mesmo que as deliberações legais emanadas da primeira constituição tenham provocado melhorias para a educação de adultos, as políticas públicas e ações, com vistas ao segmento, continuaram paralisadas e a Constituição de 1824, limitou-se apenas a um processo precário de escolarização para crianças.

É interessante pensar que no Império somente detinham a cidadania um pequeno percentual da população, que fazia parte da elite econômica, e só a essa pequena parcela a educação primária era administrada como direito, ficando isentos negros, indígenas e boa parte das mulheres. As poucas ações que foram efetivadas no periodo, tanto no ensino de jovens e adultos como na educação das crianças e adolescentes, ficaram a cargo de esforços de algumas províncias. Como reflexo dessas questões, ao final do império, $82 \%$ da população com idade superior a cinco anos era analfabeta (Haddad \& Di Pierro, 2000).

A partir de 1920, por força do crescente processo de urbanização e dos movimentos civis, oficiais e de trabalhadores, ocorreram reformas educacionais, o que culminou, na instituição da criação de escolas noturnas para adultos, por meio do Decreto $n^{\circ} 782 / A$, de 13 de janeiro de 1925, denominado Reforma João Alves.

Com a Constituição de 1934, na década de 1940, a EJA se consolidou como questão de política nacional, sendo estabelecida a obrigatoriedade e a gratuidade do ensino primário. No viés educacional, essa Constituição propôs o Plano Nacional de Educação e determinou as esferas de competência da União, dos Estados e Municipios, em matéria educacional.

De forma sistemática e contínua, a educação de adultos só ocorreria na década de 1940. Foi nessa década que a educação de adultos se consolidou como questão de política nacional, sendo estabelecida a obrigatoriedade e a gra- tuidade do ensino primário.

Embora não tenhamos a pretensão de explorar, em profundidade, todos os acontecimentos envolvendo o processo histórico da EJA, faremos uma rápida menção aos principais eventos ocorridos nas décadas de 1940 e 1950, aprofundando um pouco mais as discussões no recorte temporal compreendido entre o final da década de 1950 e durante a década de 1960 - periodos em que as articulações entre a Educação Popular e a EJA se fizeram mais substanciosas.

A questão da educação de adultos esteve atrelada à dinâmica da Educação Popular até a Segunda República. Somente com os resultados declarados pelo Censo de 1940, publicando a existência de 55\% de analfabetos acima de 18 anos, é que a educação de adultos começa a aparecer de forma independente. Foi a partir desse momento que apareceram publicações enfocando o Ensino Supletivo e se intensificaram as discussões entre aqueles que defendiam o ensino elementar como possivel solução para a contenção do analfabetismo e aqueles que optavam por iniciativas de menor prazo, como os programas de educação de adultos.

No ano de 1947, foi oficialmente lançada a Campanha de Educação de Adolescentes e Adultos (CEAA) como a primeira grande movimentação promovida pelo Estado, cujo projeto foi de Lourenço Filho, inspirado no método de Laubach. Este se ancorava nos pressupostos da psicologia experimental e defendia a promoção da alfabetização como um processo capaz de mudar a consciência dos sujeitos, reintegrando-os ao meio social e colocando-os no mesmo plano de conhecimento de direitos humanos fundamentais.

No Brasil, a CEAA, inspirada no método Laubach, contemplava a alfabetização intensiva, com duração de três meses, bem como o curso primário, dividido em dois momentos de sete meses, e a etapa final, intitulada ação em profundidade, destinada à capacitação profissional e ao desen- 
volvimento comunitário. A campanha contemplou as capitais e diversas cidades interioranas, correspondendo, simultaneamente, a um movimento de alfabetização de adultos e de extensão da escolarização nos espaços rurais.

Em um tempo consideravelmente curto, foram instituidas inúmeras escolas supletivas, movimentando esforços das esferas administrativas, de profissionais e de voluntários. Ademais, pela primeira vez, foi produzido um material didático voltado às especificidades do ensino da leitura e da escrita para os alunos adultos.

Ainda que a definição da campanha fosse a educação de adultos, ela se ocupou basicamente da alfabetização, sendo, por isso, criticada, essencialmente por se concentrar no aprendizado da escrita do nome. A campanha acabou sendo entendida, por muitos críticos do período, como "fábrica de eleitores". Estava se fazendo a recomposição dos partidos políticos, preparavam-se eleições, a educação de adultos restringia-se à alfabetização e o processo de alfabetização restringia-se a ensinar a assinar o nome, para se obter o título de eleitor, "ferrar o nome", como Paulo Freire criticou mais tarde (Fávero, 2003).

A avaliação da CEAA mostrou-se satisfatória em sua década inicial, já que, além da ampliação das classes e escolas, possibilitou o aumento da taxa de alfabetização. Contudo, o desenvolvimento da campanha passou a ser cada vez mais descentralizado e, mediante a mudança de governo, as verbas tornaram-se escassas, o que colocou as ações da campanha na dependência do voluntariado da base popular.

O lançamento da CEAA revela esse desenvolvimento de iniciativas voltadas à educação de adultos. Não obstante, as contradições e jogos de interesses, muitas vezes ocultos, envolvendo campanhas como a CEAA, como assevera Paiva (1983), muitos aspectos do entusiasmo pela educação renasceram com a CEAA, momento em que as esquerdas marxistas manifestavam uma perspectiva realista na criação de programas para adultos, mediante o fortalecimento das organizações de massas.
No ano de 1958, sob influência de orientações internacionais sobre o planejamento da educação e entendendo estar a educação atrelada com a economia do país, houve a criação da Campanha Nacional de Erradicação do Analfabetismo (CNEA). Essa campanha intentava ser um programa de caráter experimental voltado à Educação Popular, de modo geral. A CNEA se apresentava como um programa de alfabetização e educação continuada, a partir da mobilização da população. Essa campanha aparece no mesmo momento em que se deu início, no Brasil, uma nova etapa da educação dos adultos. Inicia-se, assim, a tecnificação da educação, tendo como base os avanços da economia.

Essas campanhas, embora muito significativas para a educação de adultos, não nasceram unicamente pela luta das massas em prol da contenção do analfabetismo e da consequente melhoria das condições de vida das classes populares, existiram contradições e correlações de forças na conjuntura do período. A relação da ocorrência das campanhas com os interesses políticos e embates eleitorais é reforçada por Saviani (2008, p. 136), ao mencionar que "o direito ao voto, contudo, estava condicionado à alfabetização, o que levou os governantes a organizar programas, campanhas e movimentos de alfabetização de jovens e adultos". Uma parte considerável dos programas funcionava no âmbito do Estado ou sob seu financiamento. Ancoravam-se na ideia de democratização de oportunidades de escolarização básica dos adultos, mas, também, representavam os embates políticos dos grupos que disputavam o aparelho do Estado, em suas diversas instâncias, por legitimação de ideais por meio da educação.

No mesmo período de surgimento da CNEA (1958), ocorreu no Rio de Janeiro o II Congresso Nacional de Educação de Adultos. O encontro objetivou estudar os problemas da educação dos adultos em seus variados aspectos, com fins ao seu aperfeiçoamento (Paiva, 1983). Tendo como um dos participantes o educador Paulo Freire, o congresso não se limitou a questões unicamente 
pedagógicas, mas se estendeu às discussões com enfoque de aspectos sociais e políticos, fatores inerentes ao processo educativo.

O II Congresso foi um importante marco para a EJA. Do encontro, emanaram relevantes concepções, que influenciaram o pensamento educacional brasileiro, a exemplo do "método Paulo Freire", que teve no II Congresso Nacional de Educação de Adultos os apontamentos iniciais para florescer.

Nesse ano de 1958, junto à modificação do quadro da política nacional, uma nova geração de educadores começa a aparecer. Em 1959 a oposição ao governo ganhou força e a questão do voto do analfabeto começou a aparecer com mais veemência. Em paralelo à efervescência em defesa do voto do analfabeto, emergiram movimentos de educação de adultos com o intuito não somente de formar eleitores para engordar a representação da democracia brasileira, mas, também, imbuídos do desejo de conscientização frente às estruturas do país. Nesses movimentos, cristãos e marxistas enfatizavam a importância da cultura popular e sua difusão (Paiva, 1983).

Na década de 1960, difundiram-se as ideias de Educação Popular, acompanhando a democratização da escolarização básica. Dentre os principais programas educacionais desenvolvidos, estão: o Movimento de Educação de Base, criado em 1961, com apoio do governo federal; - Movimento de Cultura Popular do Recife; os Centros Populares de Cultura; a campanha de Pé no Chão Também se Aprende a Ler, da Secretaria Municipal de Natal; o Movimento de Cultura Popular do Recife; em 1964, o Programa Nacional de Alfabetização, do Ministério da Educação e Cultura, que contou com o apoio do educador Paulo Freire. Esses anos constituíram um momento na história em que as características da EJA começaram a ser reconhecidas (Haddad \& Di Pierro, 2000).

Dentre as organizações focalizadas em educação e cultura popular, a mais longeva que se dedicou à EJA no Brasil foi o Movimento de Educação de Base (MEB). Compreendido como um organismo híbrido, vinculado à Conferência Nacional dos Bispos do Brasil (CNBB) e ao Governo Federal, sua origem, datada de 1961, relaciona-se à disposição do governo populista em apoiar a bem sucedida experiência de educação radiofônica, acumulada pela Igreja Católica em fins dos anos 1950, estruturada sob a denominação "educação de base", endereçada eminentemente às zonas rurais e abarcando catequese, alfabetização, educação moral e civica, disseminação de hábitos de higiene e saúde preventiva, organização comunitária, assessorias sindicais, cooperativismo e extensionismo rural. Vinculado à Igreja Católica e com circulação nas bases locais, o MEB foi a organização que mais tardiamente manifestou os sinais de mudança no periodo da transição democrática (Di Piero, 2000). Se por um lado, na segunda metade da década de 1970 e início dos anos 1980, as Pastorais Populares e as Comunidades Eclesiais de Base impulsionaram a atuação dos movimentos sociais do campo e da cidade, por outro, o MEB só apresentou sinais de transformação na retórica e na ação, na segunda metade dos anos 1980 , no momento em que a transição à democracia já estava delineada.

Essas campanhas e movimentos, embora muito significativas para a EJA, não nasceram unicamente pela luta das massas em prol da contenção do analfabetismo e da consequente melhoria das condições de vida das classes populares, existiram contradições e correlações de forças na conjuntura do periodo. Uma parte considerável desses programas funcionava no âmbito do Estado ou sob seu financiamento. Ancoravam-se na ideia de democratização de oportunidades de escolarização básica dos adultos, mas, também, representavam os embates políticos dos grupos que disputavam o aparelho do Estado, em suas diversas instâncias, por legitimação de ideais por meio da educação.

De modo geral, esses movimentos nasceram e foram arquitetados como representativos das situações sociais e econômicas vividas no pais e se despontaram por meio das lutas e mobiliza- 
ções do periodo. À proporção que a relevância ao direito de todo cidadão acessar os conhecimentos historicamente produzidos pela humanidade conjugou-se com a ação conscientizadora de grupos e sujeitos sociais, a educação de adultos começou a ser reconhecida, também, como um importante instrumento de ação política.

O começo dos anos 1960 pode ser destacado como um dos momentos mais caros da história da EJA. Foi no início dessa década que muitas experiências foram desenvolvidas, muitas ideias germinaram, vindo a florescer, tempos depois, mediante incorporação nas políticas nacionais de EJA. Mas, se o início dos anos 1960 é considerado um periodo áureo para a EJA, o mesmo não se pode afirmar da segunda metade da década, marcada pelo golpe militar e o consequente aniquilamento de muitas ações em prol da melhoria das condições de vida e educação das massas populares. O periodo pós 1964 marca uma nova fase na EJA (Paiva, 1983), o que faz com que a década de 1960 seja dividida em dois momentos: antes e depois do golpe. Podemos tomar o periodo anterior a 1964 como aquele em que emergiram novas ideias em matéria de EJA, e o segundo momento da década como aquele de contenção e retração. Talvez sejam exatamente as contradições e ambivalências atravessadas na década de 1960 que a torna tão significativa para os estudos de EJA, essencialmente por deixar um legado que vai ser retomado e fortalecido nas décadas posteriores.

O momento após 1964 foi marcado pela iminência de golpes e pela mobilização dos variados grupos políticos, assim como pela intensificação das forças conservadoras e pelas constantes conspirações encabeçadas por militares. Naquele mesmo período, houve o florescimento dos programas de alfabetização de jovens e adultos, que, por meio das ações das massas populares, despontavam como incômodos aos grupos de direita.

Os programas de educação de adultos instituidos entre 1961 a 1964 representavam certo risco à estabilidade do regime, sobretudo por colocar em evidência o voto das populações analfabetas e os processos de alfabetização das massas populares. Pela difusão de novas ideias sociais, os programas poderiam comprometer o processo político dos tradicionais portadores do poder. Foi mediante o temor dos prováveis efeitos dos programas de educação de adultos que se instaurou uma intensa repressão a tais iniciativas e seus mentores.

Uma elevada quantidade de programas de educação de adultos desapareceu a partir de 1964, sobrevivendo uma pequena parte, mediante reorientação de suas linhas de ação. Dentre os grandes movimentos de educação de adultos permaneceu o MEB, com reformulação de material didático, demissão de alguns técnicos e alteração do escopo do programa.

Com o reordenamento político, com vistas ao atendimento do modelo capitalista, a EJA ficou no domínio das políticas dos governos autoritários. Assim, houve repressão direta aos trabalhos envolvidos com a Educação Popular proposta por Paulo Freire. A partir de 1964, ocorreram mudanças no campo das políticas sociais e, sobretudo, no campo da educação de adultos. Em nome da suposta ordem, as liberdades foram cerceadas, as manifestações reprimidas e todas as formas de mobilização popular fortemente combatidas. 0 desaparecimento das experiências de educação de adultos ocorreu junto com o dos seus líderes, que foram perseguidos e muitos deles, a exemplo de Paulo Freire, exilados do Brasil.

O Golpe Militar de 1964 foi, portanto, o estopim para romper com as politicas de educação e atingiu os movimentos que propagavam a ideia do fortalecimento da educação e da cultura popular. De acordo Haddad e Di Pierro (2000, p. 113), "a ruptura política ocorrida com o movimento de 64 tentou acabar com as práticas educativas que auxiliavam na explicitação dos interesses populares".

\section{Desde o legado da Educação Popular: entrecruzamentos da Educação de Jovens e Adultos com o desenvolvimento da individualidade para si}

Após esse rápido retrospecto histórico, com enfoque em programas e ações que permearam 
a EJA em sua trajetória de constituição, não é dificil evidenciar que, a despeito das importantes contribuições prestadas, muitas das propostas voltadas à modalidade apresentam lacunas e inconsistências. Mesmo os movimentos que buscaram se firmar de forma engajada no combate às desigualdades sociais e contra a inculcação de ideologias dominantes acabaram sendo sucumbidos no período da ditadura. Contudo, desde a Educação Popular até a institucionalização da EJA, algumas iniciativas, calcadas em pressupostos teóricos comprometidos com a humanização e libertação dos inúmeros analfabetos brasileiros, são percebidas, não só especificamente no rol das políticas educacionais, mas, também, em iniciativas pontuais de combate à opressão, à dominação, às inúmeras formas de violências a que estão submetidos os educandos da EJA.

É nesse sentido que a tomada de consciência e a incitação à emancipação dos homens e mulheres alijados do direito à educação e, consequentemente, das apropriações dela decorrentes precisa ocupar um lugar central nas discussões. Como menciona Freire (2006), não se trata de impor à população, espoliada e sofrida, que se rebele, que se mobilize, que se organize para defender-se, vale dizer, para mudar o mundo, trata-se, na verdade, de desafiar os grupos populares para que percebam, em termos críticos, a violência e a profunda injustiça que caracterizam sua situação concreta.

No caso dos educandos da EJA, que trazem consigo toda uma trajetória de vida que, por vezes, as instituições e seus currículos teimam em desconsiderar, entende-se ser preciso considerar as vivências subjetivas desses educandos como ponto de partida para pensar a realidade, viabilizando, assim, que esses jovens, adultos e, mesmo, idosos tenham consciência de si mesmos como sujeitos históricos, imersos numa sociedade alienada e alienante, capaz de afastá-los de uma relação consciente com as objetivações do gênero humano (Duarte, 2013). É por esse viés que, no âmbito da EJA, apresenta-se de modo bastante transparente a questão ontológica da individualidade do ser. É preciso que a práxis pedagógica apresente e incite, nos jovens e adultos, a possibilidade de transpor da individualidade em si, cunhada na espontaneidade das relações estabelecidas na cotidianidade, para a individualidade para si, por meio da qual o sujeito adquire consciência dos determinantes de sua vida e, especificamente tratando da EJA, os educandos possam estabelecer uma relação consciente com o gênero humano (Duarte, 2013).

Para melhor situar as possibilidades da EJA enquanto modalidade educativa capaz de contribuir com o desenvolvimento da individualidade de educadores e educandos, é interessante pôr em tela o conceito de individualidade, essencialmente o de individualidade para si, já que a conquista da individualidade para si nas classes da EJA apresenta-se aqui como discussão nuclear. Essa conceituação dar-se-á por meio dos estudos de Duarte (2013), para quem a individualidade para si traduz as máximas possibilidades de desenvolvimento existentes para os individuos, possibilidades essas, também, relacionadas às objetivações do gênero humano. Para se chegar a esse nível de individualidade humana, é necessário, contudo, compreender a relação entre apropriação e objetivação, por meio da qual os individuos constroem sua individualidade. Desse modo, as correlações existentes entre objetivação e apropriação, enquanto dinâmica geradora da historicidade do gênero humano, não apresentam uma existência desvinculada da objetivação e da apropriação produzidas pelos indivíduos. Diferente disso, são as ações dos seres humanos que efetivam a objetivação do gênero humano, em patamares cada vez mais gerais (Duarte, 2013).

Entender que são as atividades humanas que produzem a existência dos homens e mulheres é uma premissa importante para compreender a vida que circunda os individuos e os processos dai decorrentes, dentre os quais o educativo. Contudo, isso não quer dizer que tais processos encerram em si mesmos, já que os seres humanos, ao reproduzirem sua existência individual, difundem também os elementos para a constituição de sua vida genérica.

Para Duarte (2013), quando o homem se apropria e transforma a natureza em prol de suas 
necessidades, ele também se objetiva, então, o ser humano deve se apropriar de tudo que de humano ele criou. Destarte, à proporção que o gênero humano se desenvolve, cada sujeito singular se apropria das objetivações genéricas produzidas historicamente pela humanidade, para, assim, se constituirem humanos.

Quando tratamos de estudantes jovens e adultos, que apresentam uma trajetória de vida anterior à escola, falamos de indivíduos prenhes de experiências diversas e que, portanto, que realizam constantes processos de apropriação do gênero humano. Como assevera Heller (2004), a individualidade é desenvolvimento, por essa razão, em cada momento histórico, se converte no indivíduo modos diversos de ser indivíduo, fazendo com que cada ser humano esteja em constante processo de desenvolvimento.

A educação escolar - no caso deste estudo, a EJA - tem um importante papel no desenvolvimento do educando, já que compete ao sistema educativo, por meio do ensino, a transmissão do conhecimento socialmente elaborado. Ao analisar as contribuições da Educação Popular no contexto do desenvolvimento da individualidade nas classes da EJA, é possivel pensar na atualidade dessas propostas e na real possibilidade de elas, efetivamente, promoverem um salto rumo à individualidade para si. Nesse sentido, Brandão (2002) reflete como, contemporaneamente, a Educação Popular se atualiza em diferentes práticas e concepções educativas. Divergindo de algumas ideias, que a consideram um fenômeno datado e localizado no passado, o autor afirma que a Educação Popular persiste como alicerce de variadas experiências. Para Brandão (2002, p. 155), "um trabalho de EJA, com um claro e assumido perfil de educação popular em seus pressupostos continua sendo realizado por um número bastante grande de entidades e de pessoas, de Norte a Sul do Brasil". A Educação Popular continua sendo uma sequência de propostas de um modo de educação, focado no compromisso pedagógico e no teor político, por meio de um trabalho cultural extensivo a sujeitos de classes populares, como é o caso dos da EJA, entendidos como protagonistas emergentes de um processo e que, como tal, merecem se apropriar das objetivações da humanidade.

O trabalho que a escola deve desenvolver precisa oportunizar aos sujeitos educandos a apropriação das objetivações humano genéricas, que lhes garantirão sustentação para futuras objetivações genéricas para si. Por meio de seu currículo, a escola tem, por referência às objetivações do gênero humano, que, como já mencionado na abertura deste texto, dizem respeito às elaboradas formas de recepção e reprodução da realidade (Lukács, 1966), pois o sistema primário de objetivações, compreendido como a apropriação dos utensílios, dos costumes, da linguagem, ocorre, na maioria das vezes, independente da intervenção escolar. Compete, pois, à escola contribuir para a apropriação e objetivação dos conhecimentos científicos necessários à evolução dos indivíduos e pela proposta que a EJA carrega. É, também, por meio do sistema de educação que os educandos poderão transcender de uma condição de dominação e alienação para uma condição de emancipação humana.

A assunção do compromisso que a EJA deve ter com seus jovens e adultos, no sentido de perseguir a emancipação consciente de seus educandos, é uma forma de buscar sentido para a modalidade educativa. Por intermédio dos conteúdos curriculares trabalhados e da apropriação dos saberes da experiência dos educandos é possivel que se promova, por meio da educação, mecanismos que permitam educadores e educandos realizarem o que Freire (2006) chama de leitura do mundo e avançarem no entendimento das contradições da sociedade opressora e excludente, que acaba por reduzir o desenvolvimento da individualidade humana. Desse modo, a EJA, por constituir uma modalidade educativa que atua diretamente junto à população marginalizada, com o intento de promover a humanização, aponta seu papel nuclear de auxiliar os sujeitos jovens e adultos na construção de sua própria concepção de mundo, de forma crítica e consciente.

A EJA, como modalidade educativa que compreende a educação básica, não pode se furtar 
da sua função precipua de contribuir para que os jovens e adultos se apropriem do conhecimento cientifico historicamente produzido. Em se tratando de sujeitos sociais excluídos e oprimidos em seus direitos, o contato dos sujeitos da EJA com o conhecimento sistematizado não pode ocorrer de modo acrítico, mas é preciso que tal apropriação de conhecimento garanta a problematização de suas vidas, o entendimento de suas lutas e a motivação da existência das bandeiras por eles levantadas. A EJA, por lidar com educandos dotados de especificidades, precisa levar esses educandos a niveis elevados de pensamento, que thes possibilitem indagar as razões por terem um dado tipo de vida e não outro, os motivos que os levam a entender o mundo de um modo e não de outro. É preciso que esses sujeitos indaguem por que existem grupos dominantes e grupos dominados, por que é preciso saber ler e escrever no mundo vigente, dentre tantas outras indagações que por meio da intervenção da escola, é possivel virem à tona e despertar os educandos jovens e adultos para a busca da individualidade.

Somente por meio da reflexão mediada e do insistente ato de pensar o mundo e a si mesmo é que os educandos vão tomando consciência de que para modificar as estruturas exteriores, para enfrentar as contradições da sociedade é preciso, antes disso, "fortalecer a si mesmo, desenvolver a si mesmo" (Gramsci, 1995, p. 47). Trocando em miúdos, a modificação das conjunturas sociais gestadas para o aprisionamento não pode se efetivar sem que, antes, os sujeitos sociais compreendam a si mesmos em sua pessoalidade, em sua genericidade e em sua historicidade. Dessa forma, é preciso analisar as contribuições da EJA, concebendo-a como modalidade educativa que se coloca numa dimensão mediadora entre a formação do indivíduo na cotidianidade e a formação do educando nas esferas não cotidianas da vida social (Duarte, 2013). Então, os conteúdos curriculares vinculados na EJA, uma vez bem trabalhados, constituem-se instrumentos pedagógicos capazes de levar à conscientização e à autonomia intelectual.
Obviamente, essa é uma tarefa bastante dificil, haja vista que as pressões e tensões ideológicas, mesmo as burocracias no âmbito educacional, acabam por obstacularizar essa empreitada rumo à humanização dos educandos jovens e adultos, mas a existência de desafios não pode implicar na desistência por parte daqueles que assumem para si a tarefa de perseguir uma educação humanizadora. Contudo, há de se ter em mente, essencialmente se tratando dos educadores envolvidos com a EJA, que é necessário se apropriar das condições objetivas de transformação das realidades sociais, conhecendo-as e utilizando-as a serviço do fazer pedagógico revolucionário, comprometido com os homens e mulheres das classes populares que povoam a EJA.

Tomando de empréstimo, mais uma vez, as contribuições de Duarte (2012), é possivel resumir esse pensamento sobre ser a escola um espaço proficuo de desenvolvimento da individualidade, mas, ao mesmo tempo, um veículo de inculcação de dominação ideológica, pensando em uma pedagogia que seja capaz de superar a educação escolar em suas formas burguesas, sem negar a relevância da transmissão dos conhecimentos sistematizados e científicos já produzidos pela humanidade.

Como já dito em outros momentos, a formação da individualidade para si depende de uma série de fatores, entre os quais a apropriação das objetivações genéricas da humanidade. Em se tratando do trabalho da escola de EJA, essas apropriações assumem uma dimensão que vai além da difusão sistematizada do conhecimento. Como afirmado por Duarte (2013):

Cabe ao trabalho educativo escolar um importante papel na mediação entre a relação objetivação-apropriação que se realiza no cotidiano e a relação objetivação-apropriação que se realiza nos campos da ciência, da arte e da filosofia, ou seja, das objetivações genéricas para si. (p. 213)

Focalizando especificamente da modalidade da EJA, não basta que a escola viabilize o contato dos educandos com os saberes sistematizados, mas deve incitar nos alunos a necessidade de apro- 
priação dos conhecimentos em patamares cada vez mais elevados. Como menciona Duarte (2013, p. 237), "a função social da escola é justamente produzir nos alunos, essa necessidade de conhecer mais profundamente o mundo, superando $o$ imediatismo e o pragmatismo da vida cotidiana". A EJA, enquanto modalidade da educação escolar, possui um importante papel na formação da individualidade para si, ao transmitir, de forma direta e intencional, os conhecimentos clássicos, sistematizados, não cotidianos (Saviani, 2011).

Entende-se, na esteira das formulações de Saviani (2011), que a escola deve socializar, a todos os individuos singulares, o conhecimento produzido pelo gênero humano ao longo da sua história. Contudo, existe uma ressalva, endossada especificamente pelo sistema capitalista, de que a educação para as classes populares seja diferente. Ao que tudo indica, os grupos dominantes aspiram que o conhecimento intelectual não seja acessado pelos individuos pertencentes às classes populares, a exemplo dos educandos da EJA. É nesse sentido que, a despeito do processo de alienação cristalizado nas sociedades divididas em classes, a escola contribua para a formação de individuos mais conscientes de si e da realidade em que vivem. Para que isso ocorra, a educação escolar precisa desempenhar sua função na produção das objetivações genéricas para si.

A apropriação das objetivações genéricas para si constitui, como dito por Saviani (1982), importante recurso para a participação política das massas. O conhecimento, por si só, não possui potência suficiente para transformar a realidade, mas é absolutamente necessário para que a mudança aconteça. O indivíduo dominado não consegue se libertar se não se apropriar do que os dominantes dominam, diz Saviani (1982). Isso posto, "o para-si constitui a encarnação da liberdade humana" (Heller, 1991, p. 233, grifo do original).

Desse modo, a função da escola transcende a mera adaptação dos educandos à cotidianidade. Cabe a ela construir, nos educandos, necessidades correlatas às objetivações do gênero humano e, portanto, atuar no sentido de auxiliar os estudantes na modificação da individualidade em si, por meio da incorporação da individualidade para si.

\section{Algumas considerações}

Sem ter a pretensão de apresentar considerações conclusivas sobre a temática discutida, mas tão somente esboçar as compreensões sobre as possibilidades de desenvolvimento da individualidade para si dos educandos, a partir de contribuições da EJA, este estudo se apresenta como um apoio para se pensar no desenvolvimento dos indivíduos, seja em ambientes escolares ou não escolares.

Se a formação da individualidade para si, como menciona Duarte (2013), é um processo de transformação, essa transformação certamente não se torna possivel de forma solitária, mas se realiza por meio do outro, da educação. Isso posto, a formação da individualidade para si nas classes da EJA, a partir de contribuições emanadas dos princípios da Educação Popular, é uma forma de se pensar nesse desenvolvimento humano por meio da apropriação do conhecimento historicamente produzido. Para desempenhar esse papel, a EJA, necessariamente, deve socializar os saberes cientificos, artísticos e filosóficos, haja vista que a atividade escolar deve ser um canal que estabeleça a relação consciente dos individuos com o gênero humano, propiciando, assim, a formação de uma individualidade para si.

Certamente, desenvolver a formação da individualidade para si, nos educandos jovens e adultos que povoam as classes da EJA, é uma empreitada permeada por desafios, dada as pressões ideológicas e, mesmo, a burocracia institucional. Contudo, as palavras de Gramsci (1995), podem conferir um fôlego a mais nesse desafio, quando afirma que, se a possibilidade ainda não é a plena transformação da realidade, também não se pode negar que ela já é uma realidade. Desse modo, os educadores e educandos inseridos na EJA possuem pela frente o desafio de transformar em realidade concreta os desejos de uma educação humanizadora, critica e libertária, pois não é o suficiente disseminar que existem possibilidades objetivas de modificação da EJA, com o enfrentamento das relações de dominação existentes. Retomando, mais uma vez, o pensamento de Gramsci (1995, p. 47), ".... a existência das condições objetivas - ou possibilidade, 
ou liberdade - ainda não é suficiente: é necessário 'conhecê-las' e saber utilizá-las. Querer utilizá-las". A EJA, pela utilização do saber sistematizado, deve direcionar a transição de seus educandos da individualidade em si para a individualidade para si. Nessa direção, a verdadeira transformação social e educacional deve ser feita concebendo cada educando como sujeito histórico, dotado de condições para se apropriarem das objetivações genéricas mais humanizantes.

\section{Referências}

Arroyo, M. (2001). A educação de jovens e adultos em tempo de exclusão. Revista Alfabetização e Cidadania, (11), 9-20. Recuperado de: https://aedmoodle. ufpa.br/pluginfile.php/178642/mod_resource/ content/1/11.\%20A\%20EJA\%20em\%20tempos\%20 de\%20exclus\%C3\%A30.pdf

Brandão, C. R. (2002). A educação popular na escola cidadã. Petrópolis, RJ: Vozes.

Di Pierro, M. C. (2000). As políticas públicas de educação básica de jovens e adultos no Brasil do periodo 1985/1999 (Tese de Doutorado). Pontifícia Universidade Católica de São Paulo, São Paulo, Brasil.

Duarte, N. (1999). A individualidade para-si: contribuição a uma teoria histórico-social da formação do indivíduo ( $2^{\mathrm{a}}$ ed.). Campinas: Autores Associados.

Duarte, N. (2012). Critica ao fetichismo da individualidade ( $2^{\mathrm{a}}$ ed.). Campinas, SP: Autores Associados.

Duarte, N. (2013). A Pedagogia Histórico-critica e a formação da individualidade para si. Germinal: Marxismo e Educação em Debate, 5(2), 59-72. http:// doi.org/10.9771/gmed.v5i2.9699

Duarte, N. (2013). A individualidade para si. Campinas, SP: Autores associados.

Fávero, O. (2003). Alfabetização e Educação de Jovens e Adultos no Brasil de 1947 a 1966. Revista Cultural/ SINPRO-RIO, 4(5), 04-19.

Freire, P. (1977). Educação como prática de liberdade. São Paulo: Paz e Terra.

Freire, P. (2006). Pedagogia da Autonomia: saberes necessários à prática educativa ( $34^{\mathrm{a}}$ ed.). São Paulo: Paz e Terra.

Gramsci, A. (1995). Concepção dialética da história (10 ${ }^{a}$ ed.). Rio de Janeiro: Civilização Brasileira.

Haddad, S; Di Pierro, M.C. (2000). Escolarização de jovens e adultos. Revista Brasileira de Educação, (14), 108-130. https://doi.org/10.1590/S1413-24782000000200007

Heller, A. (1991). Sociología de la vida cotidiana. Barcelona: Ediciones Península.

Heller, A. (2004). O cotidiano e a história. São Paulo: Paz e terra.
Lukács, G. (1966). Estética: la peculiaridad de lo estético: cuestiones preliminares e de principio $\left(2^{\mathrm{a}}\right.$ ed.). Barcelona: Grijalbo.

Paiva, V. P. (1983). Educação popular e educação de adultos. São Paulo: Loyola.

Saviani, D. (1982). Educação: do senso comum à consciência filosófica. São Paulo: Autores Associados.

Saviani, D. (2008). Escola e democracia. Edição comemorativa. Campinas: Autores Associados.

Saviani, D. (2011). Pedagogia Histórico-Critica: primeiras aproximações ( $11^{a}$ ed.). Campinas, SP: Autores Associados.

Saviani, D; Duarte, N. (2012). Pedagogia histórico-critica e luta de classes na educação escolar. Campinas, SP: Autores Associados.

\section{Maria Luiza Luiza Ferreira Duques}

Doutoranda em Memória: Linguagem e Sociedade pela Universidade Estadual do Sudoeste da Bahia (UESB). Mestra em Educação pela Universidade do Estado da Bahia (UNEB - Campus I). Especialista em Psicopedagogia Institucional e Clínica pela Faculdade de Guanambi (FG); Especialista em Educação a Distância pela Universidade do Estado da Bahia (UNEB - Polo Brumado); Especialista em Gestão Educacional pela Faculdade Hélio Rocha e em Práticas Docentes Interdisciplinares pela Universidade do Estado da Bahia (UNEB - Campus VI). Graduada em Pedagogia Docência e Gestão de Processos Educativos pela Universidade do Estado da Bahia (2009). Faz parte do Grupo de Pesquisa em Gestão, Organização e Políticas Públicas em Educação e do Grupo de Pesquisa em Educação, Religião, Cultura e Saúde (GEPERCS).

\section{Cláudio Eduardo Félix dos Santos}

Doutor em Educação pela Universidade Federal da Bahia. Professor adjunto da Universidade Estadual do Sudoeste da Bahia (UESB). Docente do Programa de Pós-graduação em Memória: Linguagem e Sociedade pela UESB.

\section{Endereço para correspondência}

Universidade Estadual do Sudoeste da Bahia

Estrada Bem Querer - Km 04 3293. 3391

45083-900

Candeias, BA, Brasil

Os textos deste artigo foram revisados por Zeppelini Publishers e submetidos para validação do(s) autor(es) antes da publicação. 